\title{
Modal Sosial Pekerja Minyak Kayu Putih di Desa Waplau
}

Hamiru, Abdul Latif Wabula, Said Abdurahman Assagaf, Abdi Wael, Idrus Hentihu, Rosita Umanailo, Mansyur Nawawi, Sukainap Pulhehe, Mirja Ohoibor, Riki Bugis, Edi Said Ningkeula SP, Muhammad Bula, Lutfi Rumkel, Iskandar Hamid, Irma Magfirah, Siami Prafitriyani, Belinda Sam, Wa Malmia, Syaiful Rachman, Salma Yusuf, M Yusran Zakaria, Samsia Umagusi

Universitas Iqra Buru

chairulbasrun@gmail.com

\section{Abstrak}

Tujuan penelitian ini mengidentifikasi modal sosial yang dimiliki oleh pekerja minyak kayu putih di Desa Waplau, serta menganalisis faktor dan dampak yang mempengaruhi pemberdayaan ekonomi keluarga dalam pemenuhan kebutuhan sehari-hari. Pendekatan yang dipergunakan dalam penelitian ini menggunakan pendekatan kualitatif dan Jumlah informan yang akan diwawancarai sebanyak 30 orang yang diambil secara purposive dengan pertimbangan responden dianggap sebagai pihak-pihak yang terkait untuk mencapai tujuan penelitian. Penelitian ini menggunakan teknik pengumpulan data atau teknik yang menggunakan observasi, wawancara mendalam untuk mendapatkan data kondisi keseharian serta aktivitas pekerja minyak kayu putih. Teknik analisis yang digunakan dalam penelitian ini adalah analisis data kualitatif mengikuti konsep yang diberikan Miles and Huberman dan Spradley.

Keyword: modal sosial, pekerja, minyak kayu putih, pulau buru

Tanaman kayu putih (Melaleuca cajuputi sub sp. cajuputi) di Indonesia tersebar secara alami, terutama di Pulau Jawa dan Maluku dengan memanfaatkan daunnya untuk disuling secara tradisional oleh masyarakat maupun secara komersial menjadi minyak atsiri yang bernilai ekonomi tinggi. Tanaman kayu putih sangat cocok di daerah kering karena dapat menghasilkan minyak dengan kualitas dan bobot yang lebih tinggi dibandingkan dengan daerah yang tanahnya agak basah. Namun pohon kayu putih memiliki daya adaptasi yang sangat baik, sehingga dapat tumbuh di daerah basah dan kawasan rawa sekalipun.

Pulau Buru termasuk salah satu pulau besar di Provinsi Maluku, provinsi kepulauan yang juga memiliki Kepulauan Banda, Kepulauan Kei, dan Kepulauan Aru. Luas pulau ini sekitar 9.505 km persegi, lebih luas dibandingkan Pulau Bali yang luasnya sekitar $5.636 \mathrm{~km}$ persegi. Pulau ini terdiri dari dua kabupaten yaitu Buru dan Buru Selatan. Studi terhadap pekerja minyak kayu putih menjadi penting disebabkan oleh beberapa faktor diantaranya; ketersedian jumlah tenaga kerja yang semakin terbatas, keberlanjutan usaha ikut terfragmentasi pada strata tertentu. Untuk itu, penelitian ini menjadi suatu pintu masuk atau jalan pembuka untuk menyusun strategi pelaksanaan usaha minyak kayu putih yang berkelanjutan di Pulau Buru.

Abdullah (2013) dalam penelitiannya tentang potensi dan kekuatan modal sosial dalam suatu komunitas menemukan beberapa elemen yang merupakan sumber dan energy bagi warga dalam suatu komunitas. Kekuatan modal sosial dapat diketahui melalui elemen-elemen yang terlekat dalam struktur sosial komunitas. Beberapa elemen modal sosial antara lain kepercayaan (trust), nilai dan norma timbale balik, institusi dan assosiasi, hubungan timbale balik serta jaringan. Implementasi kekuatan modal sosial dipahami dalam tiga tipologinya yaitu modal sosial sebagai perekat warga komunitas, sebagai penyambung/menjembatani dan sebagai koneksi atau akses. Modal sosial sebagai modal dasar bagi komunitas dapat mengefektifkan modal dan potensi lainnya, namun elemen yang melekat tersebut memberi manfaat dan dapat diakes oleh semua warga komunitas serta tidak bertentangan dengan standar nilai yang berlaku secara universal (Abdullah, 2013). Khoirrini (2014) dalam kajiannya tentang pengaruh modal insani dan modal sosial terhadap kinerja menyatakan bahwa pengetahuan lain dan dimensi struktural berpengaruh terhadap modal insani dan modal sosial. modal insani dan modal sosial berpengaruh positif dan signifikan terhadap kinerja. 
Penelitian ini dilakukan berdasarkan preferensi pelaksanaan program kalesang desa di Kecamatan Namlea sebagai upaya pengentasan kemiskinan di Kabupaten Buru. Selain itu, penelitian ini bertujuan untuk mendapatkan gambaran primer tentang relasi yang terbangun antara pemerintah Kabupaten Buru dengan masyarakat desa serta konsekuensi logis yang berdampak pada pemanfaatan sumberdaya di Kecamatan Namlea.

Modal sosial menjadi sangat penting didalam suatu keberlangsungan hidup kelompok atau individu di wilayah pedesaan Kabupaten Buru, karena ia bagian dari energy sosial bagi komunitasnya. Modal sosial ini beperan didalam mengikat interaksi antar pekerja minyak kayu putih, menjembatani antar kelompok sosial disuatu komunitas pekerja minyak kayu putih didalamnya atau bahkan pemasok serta pemilik lahan serta mampu menjalin kerjasama luas dengan para pemangku kepentingan yang ada.

Setiap komunitas memiliki sumber dan potensi modal sosial yang dapat diakses dan dimanfaatkan oleh anggotanya. Suatu masyarakat atau komunitas merupakan suatu potensi modal sosial, dimana komunitas atau masyarakat tersebut memberi kesadaran serta batas terhadap warga termasuk berkontribusi untuk memenuhi kebutuhan dan kepentingan bersama.

Beberapa sumber modal sosial antara lain nilai dan kearifan lokal yang mengakomodasi kepentingan bersama, kebiasaan atau tradisi, lembaga pendidikan, ajaran agama, lembaga adat dan lain-lain. Sementara potensi modal sosial antara lain ada nilai dan norma yang dapat menjadi wadah dalam mengatur untuk kepentingan bersama, ada lembaga atau institusi yang berkontribusi dalam member layanan untuk kepentingan bersama.

Kekuatan modal sosial dapat dijelaskan melalui tiga tipologinya yang meliputi pengikat, perekat (bonding social capital), penyambung, menjembatani ( bridging social capital) dan pengait, koneksi, jaringan (lingking social capital). Bahkan kekuatan modal sosial dapat menjadi pelumas yang memperlancar hubungan dan kerjasama, sehingga harapan-harapan individu dapat tercapai secara efisien dan efektif. Proses kerja kolaborasi modal sosial menjadi energy dan kekuatan komunitas, disandarkan pada sifat dan substansi yang dimilikinya yakni kepercayaan, norma dan jaringan yang tidak bisa dipisahkan satu sama lain. Hasil kerja kolaborasi modal sosial menghasilkan energy positif seperti rasa tanggungjawab, kepedulian, kejujuran, kerjasama, etos kerja positif. Keseluruhan sumber energy/kekuatan sebagai potensi sumber daya yang dimiliki oleh komunitas dapat diakses oleh setiap individu dalam meraih sejumlah harapan,kepentingan dan kebutuhan bersama. Dalam Coleman, 2005 disebutkan bentuk-bentuk modal sosial meliputi, kewajiban dan ekspektasi, potensi informasi, norma dan sanksi efektif, relasi wewenang, organisasi sosial yang dapat disesuaikan dan organisasi disengaja (Abdullah, 2013).

Cohen Komunitas adalah konstruksi simbolis tanpa parameter yang tetap yang hanya eksis dalam relasi dan oposisi dengan komunitas lain, sistem nilai (values) dan moral yang memberi rasa identity dan ikatan moral bagi anggotanya. Raymond Williams, (Outwhite,2008, 136) komunitas muncul sebagai tambahan untuk sekumpulan institusi yang mengandung hubungan yang dekat dan mendalam, horizontal, dan natural. Sementara Robert Redfield menggunakan komunitas sebagai tipe ideal pada kontinum antara dua kutub seperti tradisi- modernitas, rural-urban dan sacral- sekuler. Seiring pula dengan Ferdinand Tonnies dengan Gemeinschaft-nya yang merepresentasikan komunitasskala kecil preindustrial yang terintegrasi berdasarkan kekerabatan pertemanan dan pertetanggaan, dimana relasi sosialnya begitu dekat, lama dan bervariasi (Abdullah, 2013).

Fukuyama (1999) menyatakan bahwa modal sosialmemegang peranan yang sangat penting dalam memfungsikan dan memperkuat kehidupan masyarakat modern. Modal sosial bukan hanya aset perusahaan tetapi juga berfungsi untuk membantu mengembangkan bisnis perusahaan. Banyak perusahaan yang secara tidak langsung sudah menggunakan modal sosial dalam menjalankan perusahaannya, baik dari dalam atau luar perusahaan. Dengan demikian agar perusahaan bisa berkembang maka persoalannya bagaimana mempertahankan dan meningkatkan modal sosial. Menurut Lawang (2004) jaringan yang dibahas dalam modal sosial, menunjukan hubungan pada orang atau kelompok yang memungkinkan pengatasan masalah dapat berjalan secara efisien dan efektif. Inti dari semua ini pada dasarnya mengacu prinsip sosial yaitu bekerja sama lebih mudah mengatasi masalah dari pada bekerja sendiri. 
Definisi ini relevan untuk kegiatan ekonomik dan non ekonomik. Menurut Lesser (2000), modal sosial sangat penting bagi komunitas karena (1) memberikan kemudahan dalam mengakses informasi bagi anggota komunitas; (2) menjadi media pembagian kekuasaan dalam komunitas; (3) mengembangkan solidaritas; (4) memungkinkan mobilisasi sumber daya komunitas; (5) memungkinkan pencapaian bersama; dan (6) membentuk perilaku kebersamaan dan berorganisasi komunitas (Margadinata, 2017).

\section{Referensi}

Hamid, I. (2010). Identifikasi gulma pada areal pertanaman cengkeh Eugenia aromatica) di Desa Nalbessy Kecamatan Leksula Kabupaten Buru Selatan. Agrikan: Jurnal Agribisnis Perikanan, 3(1), 62-71.

Hentihu, Idrus (2007) Analisisi Pemasaran Tanaman Nilam (Pogostemon cablin Benth)( Studi Kasus Desa Pamotan Kecamatan Dampit Kabupaten Malang ). Other thesis, University of Muhammadiyah Malang. diakses tanggal 15 Agustus 2018.

Indra, Delfi. 2014. Pelaksanaan Manajemen Program Gerakan Masyarakat Magrib Mengaji Di Provinsi Sumatera Barat. Jurnal al-Fikrah, 2 (2); 101-113.

Magfirah, I. (2017). Efektivitas Model Pembelajaran Discovery dengan Setting Kooperatif Ditinjau dari Kemampuan Analogi dan Generalisasi Matematis Siswa Kelas VII MTs Al-Fakhriyah Makassar (Doctoral dissertation, Universitas Negeri Makassar).

Magfirah, I., Rahman, U., \& Sulasteri, S. (2015). Pengaruh Konsep Diri Dan Kebiasaan Belajar Terhadap Hasil Belajar Matematika Siswa Kelas Viii Smp Negeri 6 Bontomatene Kepulauan Selayar. MaPan: Jurnal Matematika dan Pembelajaran, 3(1), 103-116.

Nawawi, M., \& Agus Sudaryanto, S. H. (2009). Perkawinan adat sasi dan akibatnya terhadap hukum kekerabatan adat di Desa Debowae Kecamatan Waeapo Kabupaten Buru (Doctoral dissertation, Universitas Gadjah Mada).

Ningkeula, E. S. (2015). Analisis karakteristik metereologi dan morfologis DAS Wai Samal Kecamatan Seram Utara Timur Kobi Kabupaten Maluku Tengah. Agrikan: Jurnal Agribisnis Perikanan, 8(2), 81-91.

Ningkeula, E. S. (2016). Analisis karakteristik morfometri dan hidrologi sebagai ciri karakteristik biogeofisik DAS Wai Samal Kecamatan Seram Utara Timur Kobi Kabupaten Maluku Tengah. Agrikan: Jurnal Agribisnis Perikanan, 9(2), 76-86.

Pattinama, Marcus J. 2013. Potret Perempuan Buru Dan Tanggung Jawab Sosial Perusahaan Eksploitasi Hutan Di Pulau Buru, Maluku. PIRAC (Public Interest Research And Advocacy Center). http://maxmjpattinama.unpatti.org diakses tanggal 15 Agustus 2018.

Prasetiamartati, Budiati. 2006. Modal Sosial Dalam Pengelolaan Sumberdaya Perikanan. Jurnal IImu-ilmu Perairan dan Perikanan Indonesia, 13 (1); 7-19.

Pulhehe, S. (2001). Tinjauan PP Nomor 10 Tahun 1983 Menurut Hukum Islam (Perkawinan-Perceraian) (Doctoral dissertation, Universitas Airlangga).

Salaka, Fentie J. 2012. Strategi Kebijakan Pemasaran Hasil Hutan Bukan Kayu Di Kabupaten Seram Bagian Barat, Provinsi Maluku. Jurnal Analisis Kebijakan Kehutanan, 9 (1); 50-65.

Souhuwat, Ronaldo. 2013. Prospek Pengembangan Agribisnis Minyak Kayu Putih di Kecamatan Seram Barat, Kabupaten Seram Bagian Barat. Jurnal Manajemen Agribisnis, 1 (1).

Umanailo, M Chairul Basrun . 2017. “Marginalisasi Buruh Tani Akibat Alih Fungsi Lahan.” OSF. December 11. doi:10.17605/OSF.IO/9CZK2.

Umanailo, M Chairul Basrun. (2019). Strategi Bertahan Hidup Petani Padi Gogo Di Pulau Buru Survival Strategies Of The Upland Rice Farmers In Buru Island. Jurnal Ekonomi Pertanian dan Agribisnis, 3 (1);50-58..

Umanailo, M Chairul Basrun. 2017. "Kajian dan Analisis Sosiologi." OSF. December 11. doi:10.17605/OSF.IO/PV24F.

Umanailo, M Chairul Basrun. 2017. “Masyarakat Buru Dalam Perspektif Kontemporer.” OSF. December 10. doi:10.17605/OSF.IO/KZGX3.

Umanailo, M Chairul Basrun. 2018. "IImu Sosial Budaya Dasar." OSF. March 17. doi:10.17605/OSF.IO/4HPWC.

Umanailo, Rosita (2009) Studi Tentang Struktur Dan Komposisi Hutan Pantai Sendang Biru Malang Selatan. Other Thesis, University Of Muhammadiyah Malang. http://eprints.umm.ac.id/11153/ diakses tanggal 15 Agustus 2018.

Umanailo, Rosita (2013) Implementasi Kebijakan Perum Perhutani Dalam Pengelolaan Sumberdaya Hutan Bersama Masyarakat Sekitar Hutan (Studi Di Wilayah Perum Perhutani Kph Malang). Masters thesis, University of Muhammadiyah Malang. http://eprints.umm.ac.id/30546/ diakses tanggal 15 Agustus 2018.

Uniqbu, Pusat S P d P, Abdul L Wabula, Said A Assagaf, Abdi Wael, Idrus Hentihu, Rosita Umanailo, Hamiru, et al. 2018. "Gerakan Bupolo Magrib Mengaji Sebagai Media Aktualisasi Pruralisme." OSF. October 6. doi:10.17605/OSF.IO/FDZ3N.

Uniqbu, Pusat S P d P, Belinda Sam, Lutfi Rumkel, Abdi Wael, Idrus Hentihu, Rosita Umanailo, Hamiru, et al. 2018. "Feminisme Perempuan Adat Di Pulau Buru." OSF. October 7. osf.io/j9r8u.

Uniqbu, Pusat S P d P, Edi S Ningkeula, Belinda Sam, Lutfi Rumkel, Abdi Wael, Idrus Hentihu, Samsia Umasugi, et al. 2018. "Daya Dukung Kawasan Pedesaan Di Pesisir Barat Pulau Buru Untuk Pengembangan Wisata Bahari." OSF. October 7. doi:10.17605/OSF.IO/MYFS6.

Uniqbu, Pusat S P d P, M Y Zakaria, Salma Yusuf, Syaiful Rachman, Wa Malmia, Belinda Sam, Abdul L Wabula, et al. 2018. "Gerakan Buru Membaca Sebagai Media Pembelajaran Masyarakat Di Kabupaten Buru." OSF. October 7. doi:10.17605/OSF.IO/NECH5.

Zakaria, M. Y. (2017). Karakteristik Penyelesaian Masalah Matematika ditinjau dari Kecenderungan Kepribadian Pada Siswa kelas X SMA Negeri 16 Makassar (Doctoral dissertation, Pascasarjana). 